\title{
Rapid method for determination of dehydro abietic acid in gum rosin and disproportionate rosin by proton nuclear magnetic resonance spectroscopy
}

\author{
Ravindra Kumar*, K. Chattopadhyay, Bantu Bhasker, Sujit Mondal, \\ J. Christopher and G.S. Kapur
}

\begin{abstract}
In present work a simple, direct and rapid method developed based on proton nuclear magnetic resonance spectroscopy for the quantitative determination of dehydroabietic acid in gum rosin and disproportionated rosins and validated. This method can also be applied to the determination of other acids of gum rosins like abietic acid, pimaric acid isopimaric acid, palustric acid, neo abietic acid, levopimaric acid, tetrahydro abietic acid, dihydro abietic acid. Dehydroabietic acid has been estimated using aromatic proton while vinyl propton was used for estimation of other acids in gum rosins. Analysis of rosin acid methyl ester derivative in disproportionated rosins was also carried out by gas chromatography-mass spectroscopy to identify peak of dehydro abeitic acid along with abeitic acid based on their mass fragmentation pattern and quantified using gas chromatography with flame ionization detector. Good correlation was observed between the results of gas chromatography with flame ionization detector with newly developed nuclear magnetic resonance method.
\end{abstract}

\section{KEYWORDS}

Dehydro abietic acid, disproportionate rosin, nuclear magnetic resonance spectroscopy, gas chromatography-mass spectroscopy.

Indian Oil Corporation Limited, Research \& Development Centre, Sector-13, Faridabad 121007, Haryana, India

*Corresponding author; email:

kumarr88@indianoil.in

\begin{abstract}
INTRODUCTION
Rosin acid is a raw material used in adhesives industry either as such or derivatives. Three sources of rosin are used for resin manufacture viz., gum rosin, wood rosin and tall oil rosin, all generated from the pine tree. Rosin acid unlike hydrocarbon resins, is not a polymer. It is a blend of distinct molecules. Rosin acid is a mixture of eight closely related rosin acids characterized by three fused six-carbon rings, double bonds that vary in number and location, and a single carboxylic acid group. The ratio of these isomers in rosin depends on the collection method and the species of the tree from which the rosin was harvested.
\end{abstract}

Gum rosin was once the only commercial source of rosin. It is the oleoresin (pine gum) of the living pine tree. The harvesting of the oleoresin is simple, involving only periodic wounding of the tree and collecting the sap into cups. Gum rosin contains abietic acid (AA) (Fig. 1a), dehydro abietic acid (DAA) (Fig. 1b), pimaric acid, isopimaric acid, palustric acid, neo abietic acid, levopimaric acid, tetrahydro abietic acid and dihydro abietic acid. Major component of gum rosin is $A A$, which has a conjugated diene and is easily oxidizable. The stability of gum rosin increases by disproportionation reaction to produce disproportionate rosin (DPR) that is resistance to oxidation. Dehydro abietic acid (DAA) is the main component of DPR rosin, an important rosin derivative used industrially in paper sizing, coating compositions, synthetic resins and especially an emulsifying agent in the manufacturing of styrene butadiene rubber. There are several commercial grades of DPR rosins available in the market containing 30 to 
$65 \%$ DAA. Variation in disproportion processes causes considerable variation in DAA content as result of incomplete disproportion of the conjugated diene acids such as abietic, neoabietic and palustic acids. This reduces the overall stability to oxidation and the usefulness of the end product, hence need for a method of DAA quantitation.

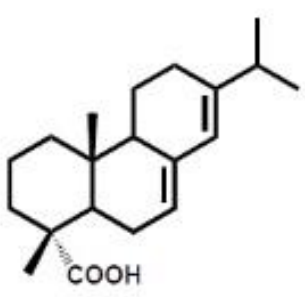

a.

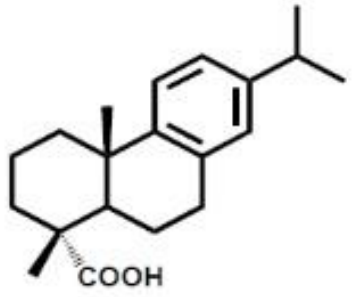

b.
Fig. 1 Structure of a. Abietic Acid and b. Dehydro Abietic Acid

The need to find a simple, rapid, accurate and reproducible method for quantitative analyses of DAA in gum rosins and DPR for the usefulness of gum resins. There is no method available for direct estimation of Dehydro Abietic Acid and different isomers of Abeitic acid in gum rosin and DPR. Separation of the methyl esters of resin acids has been carried out by gas chromatography (Huddy JA, 1959; Nestler and Zinkel, 1963) and estimation of diterpene and fatty acids (Joye et al., 1974; Nestler and Zinkel, 1967; Zingle and Engler, 1977; Holmbom et al., 1974; Foster and Zinkel 1982) by gas-liquid chromatography and capillary gas chromatography-mass spectrometry. Total abietic type acids can be determined by acid isomerization and determination of the abietic acids by the gas liquid chromatography of the methyl esters (Hans and Zinkel, 1991; Hanson and Kulkarni 1972; Mayr et al., 1982). In particular situations, other techniques may be more suitable than gas chromatography, first due to hydrogen bonding; unmodified fatty acids and rosin acids cannot be volatilized at atmospheric pressure without undergoing decomposition. So, it is necessary to convert the free acids to the more volatile and more stable methyl esters, prior to chromatographic separation. Secondly, the presence of fatty acid esters in the sample would result in transesterification during the derivatization step that may affect the results.

In the present work, a new analytical method based on proton nuclear magnetic resonance ( ${ }^{1} \mathrm{H}$ NMR) spectroscopy has been developed for the direct estimation of dehydroabietic acid in gum rosin and disproportionated rosins. This method can also be applied for the determination of other acids of gum rosins like Abietic acid (AA), pimaric acid, isopimaric acid, palustric acid, neo abietic acid, levopimaric acid, tetrahydro abietic acid, dihydro abietic acid. DAA has been estimated using aromatic proton and other acids have been estimated using unsaturated proton by quantitative NMR (qnmr). Gas chromatography-mass spectroscopy (GC-MS) analysis of methyl ester derivative of rosin acid and its DPR was carried out for detection of Dehydro Abeitic acid (DAA) based on their mass fragmentation pattern (EI, $70 \mathrm{eV}$ ) and NIST library matching. However, their content in samples was estimated by gas chromatography with flam ionization detector (GC-FID). The outcome of NMR analysis was validated with GC results to check the appropriateness of the developed method, and good correlation was found.

\section{RESULTS AND DISCUSSION}

All gum rosins and DPR NMR spectra were recorded in acetone-d6 instead of Chloroform$\mathrm{d}$ due to auto-oxidation of gum rosins in Chloroform-d. This auto oxidation of gum resins in chloroform starts after 30 minutes and the residual peak of chloroform at 7.26 ppm overlap with DAA peaks in $1 \mathrm{H} N M R$ spectrum of gum rosin and DPR; hence acetone-d 6 is the best solvent for estimation of DAA.

The chemical shifts of the protons were more difficult to assign because of extensive overlap caused mainly by proton-proton coupling interactions. The assignments of $1 \mathrm{H} \mathrm{NMR}$ spectrum of gum rosin and DPR have been assigned as per Landucci et al., 1991, which is given in Table $1 .{ }^{1} \mathrm{H}$ NMR spectra of different origin gum rosins are given in Fig. 2 with their olefinic and aromatic regions and ${ }^{1} \mathrm{H}$ NMR spectrum of DPR is given in Fig.3. 
The vinyl protons of abietic acid (2) appeared at $5.76 \mathrm{ppm}(1 \mathrm{H}, \mathrm{s})$ and at $5.35 \mathrm{ppm}(1 \mathrm{H}$, broad), levopimaric acid (3) appeared at 5.56 ppm $(1 \mathrm{H}, \mathrm{s})$ and at $5.16 \mathrm{ppm}(1 \mathrm{H}$, broad), and only one vinyl proton in palustric acid (4) appeared at $5.38 \mathrm{ppm}(1 \mathrm{H}, \mathrm{s})$. The protons of neoabietic acid (5) appeared at $6.21 \mathrm{ppm}(1 \mathrm{H}$, s) and Pimaric acid $(6)$ at $4.95-4.84(2 \mathrm{H}, \mathrm{m})$ and 5.84-5.71 $(1 \mathrm{H}, \quad \mathrm{m})$. For quantitative determination of the component acids present in the rosin acid, the respective areas of the vinyl proton signals were used throughout this work. Dehydroabietic acid which appeared at 7.34-6.87 ppm (3H) (1) and neoabietic acid (5) were able to be determined without being disturbed by the presence of other rosin acids. Abietic acid (2), levopimaric acid (3), palustric acid (4) and pimeric acid (6) were interfered by other rosin acid peaks which are also estimated using their characteristic peak integrations which is given in Table 1. Stacked $1 \mathrm{H}$ NMR spectra of reactant (Gum rosin) and treated rosin (DPR) has been given in Fig. 4.

\begin{tabular}{llll}
\hline S. No & Rosin Acids & Chemical Shift used for quantification (ppm) & No of Protons \\
\hline 1 & Dehydroabietic acid & $7.34-6.87\left(\mathrm{I}_{\mathrm{DA}}\right)$ & $3 \mathrm{H}$ \\
2 & Abietic acid & $5.76\left(\mathrm{I}_{\mathrm{A}}\right)$ & $1 \mathrm{H}$ \\
3 & Levopimaric acid & $5.16\left(\mathrm{I}_{\mathrm{L}}\right)$ & $1 \mathrm{H}$ \\
4 & Palustric acid & $5.38\left(\mathrm{I}_{\mathrm{P}}\right)$ & $1 \mathrm{H}$ \\
5 & Neoabietic acid & $6.21\left(\mathrm{I}_{\mathrm{N}}\right)$ & $1 \mathrm{H}$ \\
6 & Pimeric acid & $4.95-4.84\left(\mathrm{I}_{\mathrm{PM}}\right)$ & $2 \mathrm{H}$ \\
& & $5.84-5.71\left(\mathrm{I}_{\mathrm{Pm}}\right)$ & \\
\hline
\end{tabular}

Table 1 Characteristic peaks of different type rosin acids

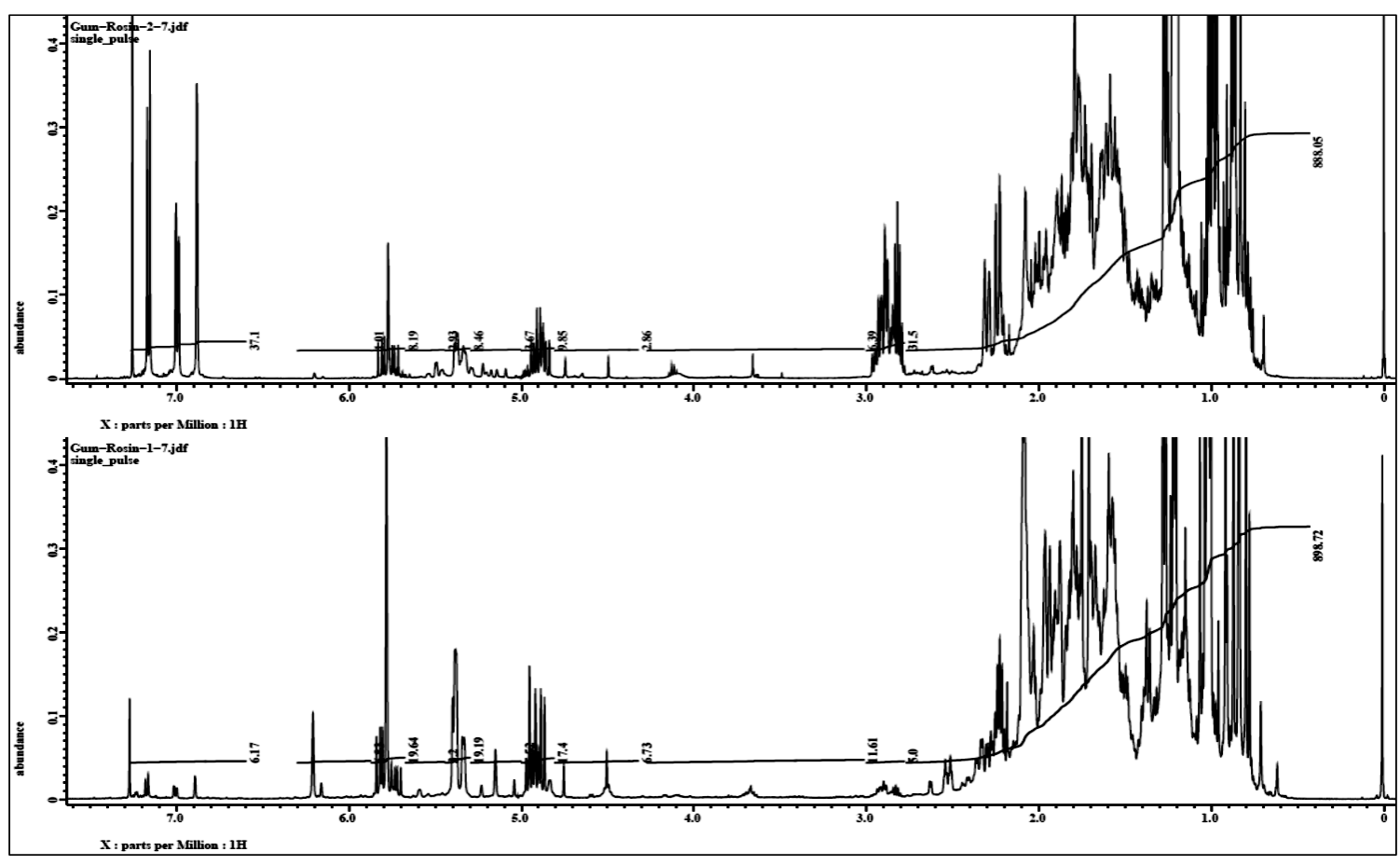

Fig. $2{ }^{1} \mathrm{H}$ NMR spectra of different origin Gum rosins 


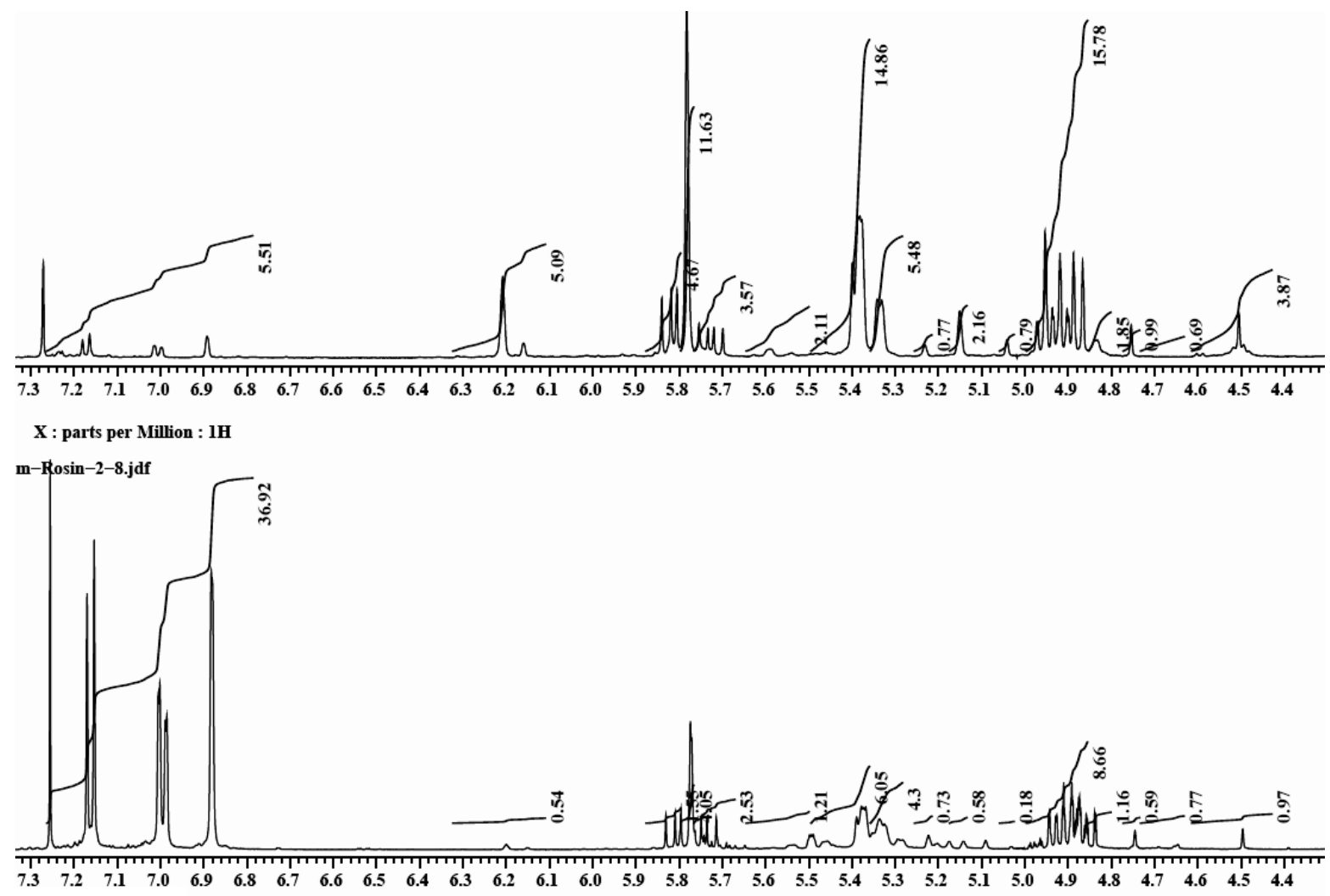

$X: \mathbf{p p m}$

Fig. 3 Olefinic and aromatic regions of disproportionate rosin ${ }^{1} \mathrm{H}$ NMR spectra

DAA has been estimated using aromatic proton and other acids have been estimated using vinyl proton. Three aromatic protons integration of DAA has been used for quantitative estimation of DAA. The amount (\%) of DAA $\left(W_{D A}\right)$ has been estimated by quantitative ${ }^{1} \mathrm{H}$ NMR experimentation while compared with known amount of HMDSO ( $W_{\text {HMDSO) }}$. The following equations have been used for the estimation.

$$
\begin{aligned}
\mathrm{W}_{\mathrm{DA}} & =\left(\mathrm{W}_{\text {HMDSO }} * \mathrm{M}_{\mathrm{DA}} * \mathrm{~N}_{\text {HMDSO }} * \mathrm{I}_{\mathrm{DA}}\right) / \\
\left(\mathrm{M}_{\text {HMDSO }} * \mathrm{~N}_{\mathrm{DA}} * \mathrm{I}_{\text {HMDSO }}\right) & \\
= & 0.11085 *\left(\mathrm{~W}_{\text {HMDSO }} * \mathrm{M}_{\mathrm{DA}} * \mathrm{I}_{\mathrm{DA}}\right) / \\
\left(\mathrm{N}_{\mathrm{DA}} * \mathrm{I}_{\text {HMDSO }}\right) & -\cdots
\end{aligned}
$$

Where, $W_{D A}=$ Weight of component to be estimated, $\mathrm{W}_{\text {HMDSO }}=$ Weight of HMDSO taken, $M_{D A}=$ Molecular weight of component, $I_{D A}=$ Integral value of the relevant chemical shift region of the component, $\mathrm{N}_{\mathrm{DA}}=$ Number of protons in the chemical shift region with integral $I_{D A}, I_{H M D S O}=$ Integration value for HMDSO at $0.07, \mathrm{~N}_{\text {HMDSO }}=18$ and $\mathrm{M}_{\text {HMDSO }}=$ 162.38 .

An analogous equation has been used to estimate other acids and given as follows:

$$
\begin{aligned}
& \mathrm{W}_{\mathrm{x}}=\left(\mathrm{W}_{\text {HMDSO }} * \mathrm{M}_{\mathrm{x}}{ }^{*} \mathrm{~N}_{\text {HMDSO }} * \mathrm{I}_{\mathrm{x}}\right) / \\
& \left(\mathrm{M}_{\text {HMDSO }} * \mathrm{~N}_{\mathrm{x}}{ }^{*} \mathrm{I}_{\text {HMDSO }}\right) \\
& =0.11085 *\left(\mathrm{~W}_{\text {HMDSO }} * \mathrm{M}_{\mathrm{x}}{ }^{*} \mathrm{I}_{\mathrm{x}}\right) / \\
& \left(\mathrm{N}_{\mathrm{A}}{ }^{*} I_{\text {HMDSO }}\right)
\end{aligned}
$$

Where, $W_{x}=$ Weight of acid to be estimated, $\mathrm{W}_{\text {HMDSO }}=$ Weight of HMDSO taken, $\mathrm{M}_{\mathrm{x}}=$ Molecular weight of acid, $\mathrm{I}_{\mathrm{x}}=$ Integral value of the relevant chemical shift region of the acid as given in Table 1, $N_{x}=$ Number of protons in the chemical shift region with integral $I_{x}$ as given in Table $1, I_{\text {HMDSO }}=$ Integration value for HMDSO at 0.07, $\mathrm{N}_{\text {HMDSO }}=18$ and $\mathrm{M}_{\text {HMDSO }}=162.38$. 
Characteristics peak of abietic acid at $5.76 \mathrm{ppm}$ overlapped with pimeric acid one proton (Ipm), so $\mathrm{I}_{\mathrm{A}}$ has been estimated as per eq. 3 .

$I_{A}=I p m-I_{P M} / 2------(3)$

DAA estimated in DPR of different origin gum rosins by ${ }^{1} \mathrm{H}$ NMR is, given in Table II. Analysis of rosin acid methyl ester derivative in DPR was carried out in GC-MS to identify peak of Dehydro Abeitic acid (DAA) along with Abeitic acid (AA) based on their mass fragmentation pattern (EI, $70 \mathrm{eV})$. The peak eluting at 22.185 minutes was compared to Dehydroabeitic acid (DAA) and unambiguously confirmed by NIST library matching. Dehydroabeitic and Abeitic acid were quantified in DPR treated rosin acids using GC-FID (Fig. 5) and results were compared with newly developed NMR method (Table 2). A good correlation was observed between NMR and GC results for DAA in DPR. Other rosin acids have also been estimated in different origins DPR by 1 H NMR spectroscopy, which is given in Table 3.

After the synthesis of DPR from gum rosins, it has been observed that, $75-80 \%$ of abeitic acid, neoabeitic acid and palusteric acid were converted in DAA while $40-45 \%$ of pimeric acid and isopemeric acids were converted in DAA. It is important to mention here that isomerization of levopimaric acid and neoabietic acid into abeitic acid followed by auto-oxidation to DAA was observed in Chloroform- $d$ after a certain time ( 6 hours). Several investigations have been made for the transformations of individual component resin acids during rosin disproportionate (Fleck and Palkin 1937; Fleck and Palkin1938; Mostafalu et al., 2017)

\section{CONCLUSION}

A simple, direct and rapid ${ }^{1} \mathrm{H}$ NMR method for the quantitative determination of dehydroabietic acid in gum rosin and disproportionated rosins was developed and validated. This NMR method has also applied for the determination of other acids of gum rosins like Abietic acid (AA), pimaric acid isopimaric acid, palustric acid, neo abietic acid, levopimaric acid, tetrahydro abietic acid and dihydro abietic acid.

\begin{tabular}{lcc}
\hline Sample & NMR & DAA (Wt\%) \\
\hline GR-1 & 59.6 & GC \\
GR-2 & 52.1 & 58.9 \\
GR-3 & 53.5 & 52.2 \\
GR-4 & 54.7 & 53.5 \\
GR-5 & 60.7 & 54.3 \\
\hline
\end{tabular}

Table 2 Dehydroabeitic acid in DPR by $1 \mathrm{H}$ NMR and GC method 


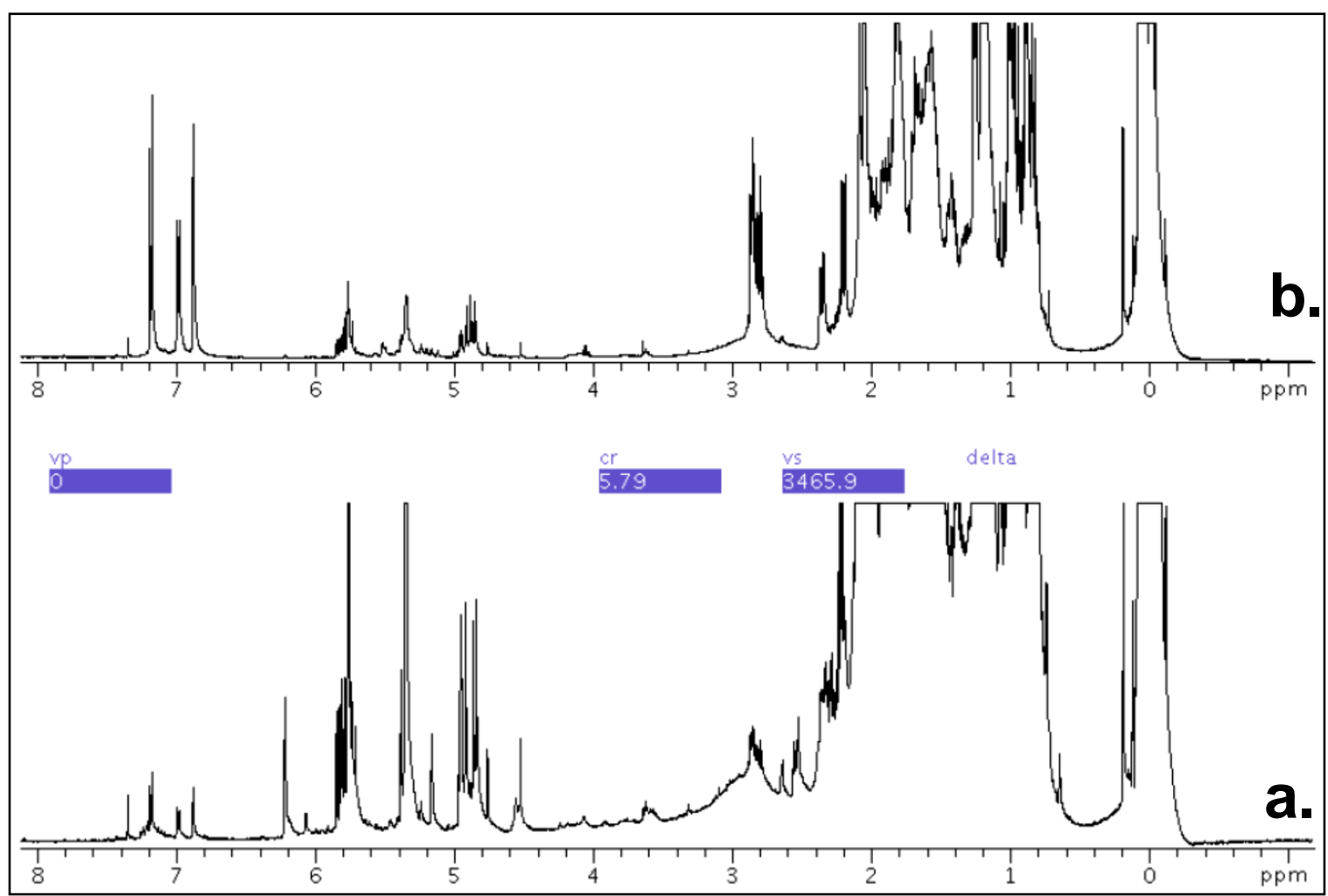

Fig.4: Stacked 1H NMR spectra of a. reactant (Gum rosin) and b. treated rosin (DPR)
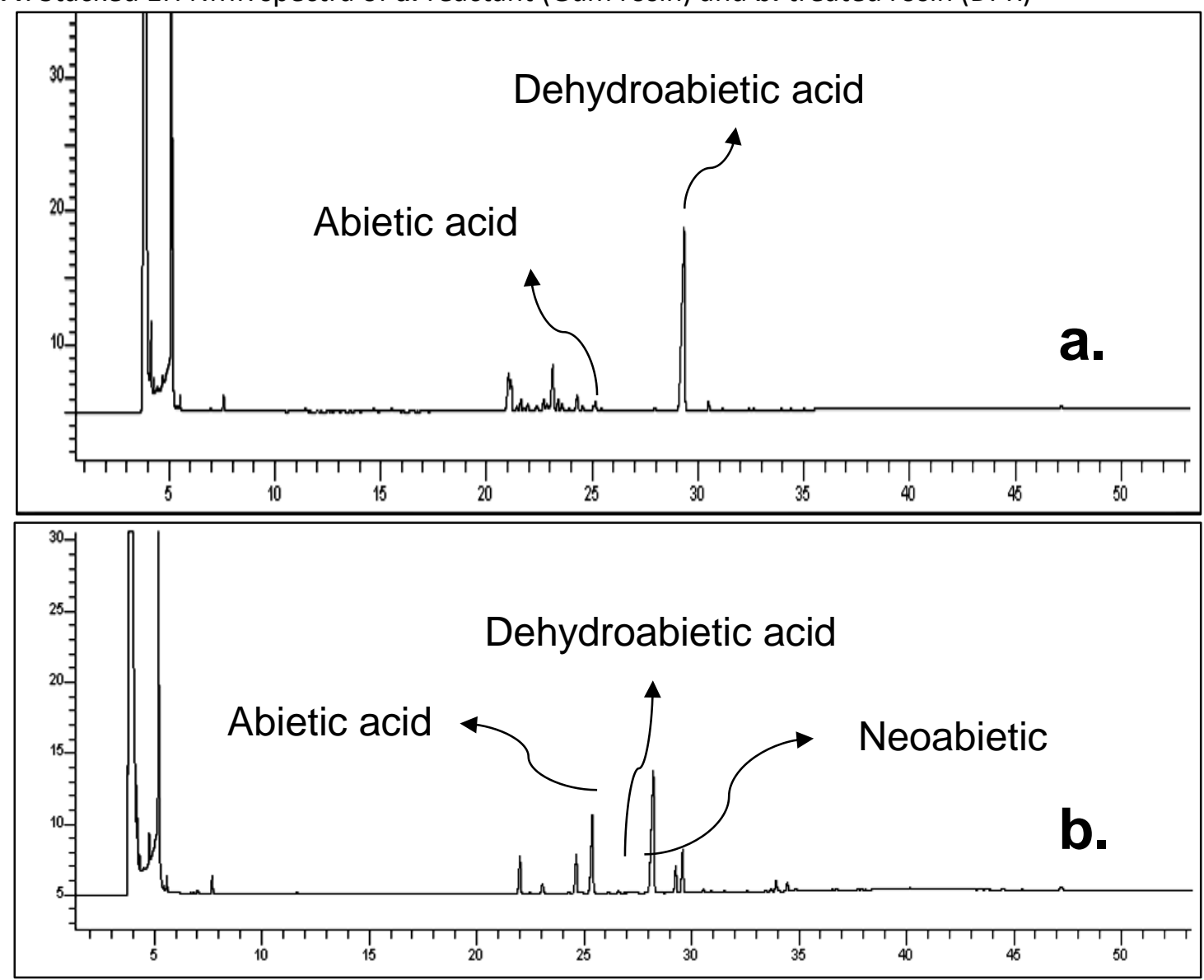

Fig. 5 GC-FID chromatogram of methyl ester derivative of gum rosin acid (b.) and it's DPR (a.) 


\begin{tabular}{lcc}
\hline Sample & & DAA (Wt $\%)$ \\
& NMR & GC \\
\hline GR-1 & 59.6 & 58.9 \\
GR-2 & 52.1 & 52.2 \\
GR-3 & 53.5 & 53.5 \\
GR-4 & 54.7 & 54.3 \\
GR-5 & 60.7 & 61.2 \\
\hline
\end{tabular}

Table 2 Dehydroabeitic acid in DPR by $1 \mathrm{H}$ NMR and GC method

\section{MATERIAL AND METHODS Sample}

Gum resins from China and India origin and their DPR have been used for this study.

\section{Synthesis of DPR}

Disproportionate reaction of gum rosin was carried out by using Palladium charcoal catalyst. In Disproportionation experiment, $100 \mathrm{~g}$ of gum rosin was heated under nitrogen (hot plate) in a $250 \mathrm{ml}$ of glass bottle equipped with magnetic stirrer and thermometer. The $5 \%$ Pd on charcoal catalyst $(290 \mathrm{mg}$ ) was added when temperature reached to $230^{\circ} \mathrm{C}$ and then the reaction temperature was slowly increased to $270^{\circ} \mathrm{C}$. The mixture was heated at $270^{\circ} \mathrm{C}$ for 6 hours. The reaction mixture was cooled to RT and then the solid was dissolved in dichloromethane and filtered. The final product, DPR was obtained after removal of the solvent.

\section{Sample Preparation}

The sample of gum rosin and DPR ( 40 to $60 \mathrm{mg}$ ) were weighed into a NMR tube with its cap fitted at the top and allowed it to reach equilibrium. The standard reference compound ( 5 to $15 \mathrm{mg}$ ) was then added and recorded the amount up to 5 digits for both the cases. The sample was then diluted with $\mathrm{CDCl}_{3}$ $(\sim 0.7 \mathrm{~mL})$ and recorded the spectra.

A highly sensitive balance (Sartorius BP 211D, Gottingen, Germany) was used to weigh the sample and standard (upto 5-decimal). The methyl peak of HMDSO was used as a frequency reference and set to $0.07 \mathrm{ppm}$ downfield from TMS.

\section{Selection of a Suitable Reference Compound for Quantitative NMR Spectroscopy}

For quantitative $1 \mathrm{H}$ NMR spectroscopy, hexamethyldisiloxane (HMDSO) has been selected as an excellent internal reference standard which meets all the desirable characteristics. Purity of HMDSO used has also been thoroughly checked. It has been found that increasing the relaxation delay from $5 \mathrm{~s}$ to 20 s does significantly influences the integral value and so most of the samples were recorded with 20 s relaxation delay.

\section{NMR Method}

All proton NMR spectra were recorded on a Jeol ECA-500 NMR spectrometer operating at the proton frequency of $500 \mathrm{MHz}$, spectral width $7512 \mathrm{~Hz}(-2.5-12.5 \mathrm{ppm}), 90^{\circ}$ pulse $=10.7$ $\mu \mathrm{s}$, relaxation delay $=20 \mathrm{~s}$, digital resolution $0.49 \mathrm{~Hz} /$ point. 32 repetitions were averaged with $32 \mathrm{~K}$ data point and 6.38 minutes experimental time. All the NMR spectra were integrated after baseline correction, and a mean of minimum three integration values has been taken for each calculation.

\section{GC and GC-MS}

The conversion of acids present in the gum rosin samples to methyl ester was carried out by N,N-Dimethylformamide Dimethyl Acetal (DMF-DMA) reagent as per the ASTM D 5975 method. $0.5 \mathrm{gm}$ rosin acid was taken in an appropriate anhydrous vial and dissolved in approximately $0.5 \mathrm{~mL}$ of toluene. Then 
approximately $1 \mathrm{~mL}$ of DMF-DMA was added to the mixture and maintained at $50^{\circ} \mathrm{C}$ for 120 minutes. Finally, the resultants were used for GC analysis

The qualitative analysis was carried out on using Bruker GC-MS (Scion SQ, 436-GC) with the help of a polar column; (RTX-2330; $60 \mathrm{~m} \mathrm{x}$ $0.32 \mathrm{~mm}$ ID $\times 0.2 \mu \mathrm{m}$ ) procured from $\mathrm{M} / \mathrm{s}$ Restek to identify the compound. However, quantification of DPR was achieved using PerkinElmer Clarus 500 GC instrument equipped with FID and split/split less injector. The following analytical conditions were used during analysis in GC-FID and GC-MS respectively.

\section{Parameters of GC-FID}

Split ratio: 10:1

Oven programme: $150{ }^{\circ} \mathrm{C}$ (5 minutes hold) $3^{\circ} \mathrm{C} /$ minute $-250^{\circ} \mathrm{C}$ ( 15 minutes hold)

Injector and Detector temperature: 300 and $320^{\circ} \mathrm{C}$ respectively

Carrier (Helium) gas Flow: $1.5 \mathrm{ml} / \mathrm{min}$

Sample injection volume: $0.2 \mu \mathrm{l}$.

\section{Parameters of GC-MS}

Operating Mode: Scan mode with 10:0 split

Carrier Flow: $1 \mathrm{ml} / \mathrm{min}$ column flow for GC-MS

Oven programme: $150{ }^{\circ} \mathrm{C}$ ( 5 minutes hold) $3^{\circ} \mathrm{C} /$ minute $-250^{\circ} \mathrm{C}\left(15\right.$ minutes hold) $250^{\circ} \mathrm{C}$ (10 minutes hold)

Injector temperature: $300^{\circ} \mathrm{C}$

MS Source and transfer line: 230 and $250{ }^{\circ} \mathrm{C}$ respectively

Ionization: $\mathrm{El}(70 \mathrm{eV})$

Scan Range: $\mathrm{m} / \mathrm{z} 40$ - 500

Injection Volume: $0.4 \mu \mathrm{l}$.

\section{REFERENCES}

Fleck, E.E. and Palkin, S. 1937, 'atalytic isomerization of the acids of pine oleoresin and rosin', J. Am. Chem. Soc, vol. 59, pp. 1593-1595.

Fleck, E.E. and Palkin, S. 1938, 'On the nature of pyroabietic acids', J. Am. Chem. Soc, vol. 60, pp. 921-925.

Foster, D.O. and Zinkel, D.F. 1982, 'Qualitative and quantitative analysis of diterpene resin acids by glass capillary gas-liquid chromatography', $J$. Chromatogr, vol. 248, no. 1, pp. 89-98.

Han, J.S. and Zinkel, D.F. 1991, 'Gas chromatography of resin acids with a BDS fused- silica capillary column', Naval Stores Rev, vol. 101, pp. 13-16.

Hanson, J.C. and Kulkani, M.V. 1972, 'Open-tubecolumn gas chromatography of rosin fluxes', Anal. Chem, vol. 44. no. 9, pp. 1586-1589.

Holmbon, B., Avela, E., Pekkala, S. 1974, 'Capillary gas chromatography-mass spectrometry of resin acids in tall oil rosin', J. Am. Oil Chem. Soc, vol. 51, no. 397.

Huddy, J.A. 1959, 'Resin Acids. Gas chromatography of their methyl esters', Anal. Chem, vol. 31, no. 11, pp. 1754-1756.

Joye, Jr. N.M., Rouveax, A.T. and Lawrence, R.V. 1974, 'Improved procedure for the analysis (GLC) of resin acids', J. Am. Oil Chem. Soc., vol. 51, no. 5, pp. 195-197.

Landucci, L.L. and Zinkel, D.F. 1991, 'the $1 \mathrm{H}$ and $13 \mathrm{C}$ NMR spectra of the Abietadienoic resin acids', Holzforschung, vol. 45, no. 5, pp. 341-346.

Mayr, M., Lorbeer, E., Kratzl, K. 1982, 'chromatographic separation of diterpene acids on glass capillary columns of different polarity', J. Am. Oil. Chem, vol. 59, no. 1, pp. 52-57.

Mostafalu, R. et al. 2017, 'The use of palladium nanoparticles supported on active carbon for synthesis of disproportionate rosin (DPR)', J Nanostruct Chem, vol. 7, pp. 61-66.

Nestle, F.H.M. and Zinkel, D.F. 1963,' Separation of the methyl esters of resin acids by gas liquid chromatography', Anal. Chem, vol. 35, no. 11, pp. 1747-1749.

Nestler, F.H.M. and Zinkler, D.F. 1967, 'Quantitative gas-liquid chromatography of fatty and resin acid methyl esters', Anal. Chem., vol.39, pp. 1118-1124. Zingle, D.F. and Engler, C.C. 1977, 'Gas-liquid chromatography of resin acid esters',J. Chromatogr, vol. 136, no. 2, pp. 1118-1124. 